\title{
ZETA Converter for Boost up operation in low frequency instrumentation used in power grid application
}

\author{
Mr. D.Praveen Sangeeth Kumar ${ }^{1}$, Mr. S. Prem Kumar ${ }^{2}$ \\ 1. PG student Bharath Institute of Science and technology \\ 2. Assistant Professor, Bharath Institute of Science and Technology
}

\begin{abstract}
This system where the step-up converter is implemented by an isolated Zeta converter. In this case, the ZETA converter has two functions: To provide electrical isolation and synthesize a rectified sinusoidal current waveform similar to the power grid. This paper presents a dynamic modeling study for a ZETA converter working in discontinuous conduction mode (DCM) applied to low power renewable energy sources using the generalized switch averaging technique. The modeling is performed considering only resistive loads. The whole system consists of a ZETA converter, using a sinusoidal pulse width modulation (PWM), associated with a full-bridge (FB) inverter, operating at low frequency, in order to synthesize a sinusoidal waveform at its output. Thus, the system works as a sinusoidal low power source. Initially it is presented a brief analysis of thesystem, as well as the characteristics that made possible the dynamic analysis in DCM. The generalized switch averaging technique is discussed, and also the small-signal analysis of the ZETA converter. In order to validate the current study experimental and simulation results are presented
\end{abstract}

\section{INTRODUCTION}

Several topologies have been researched in search of a structure which not only is able to fulfill the requirements of the power factor and the amount of harmonics injected in a line foreseen in the norms, but which would also show the best ensemble of characteristics. Although being the most frequently employed and studied structure, the boost converter presents some limitations in its application, for it is not a naturally isolated structure and because it only operates as step up voltage. As an alternative to these limitations the Zeta converter operating in discontinuous mode applied to the power factor correction was proposed (D.C. Martins, 1994)

The Zeta converter showed itself as very attractive because it operates as step up as well as step down voltage, beside the fact of being a naturally isolated structure and processing power at one single stage. But in applications which imply high power, the operation of a converter in discontinuous mode is not attractive because it results in high RMS values of the currents causing high levels of stress in the semiconductors. Aiming to extend the alternative by use of the Zeta converter in power factor correction to applications in higher powers, and having in mind the main characteristics and advantage of this converter in face of the limitations of the boost converter, this paper presents the study of the Zeta converter operating in continuous conduction mode for power factor correction by using the average current

Solar energy can be converted into other forms of energy, such as heat and electricity. In the 1830s, the British astronomer John Herschel used a solar thermal collector box (a device that absorbs sunlight to collect heat) to cook food during an expedition to Africa. Today, people use the sun's energy for lots of things. Solar energy can be used to heat a fluid such as water in solar collector panels. Simple types use flat collector panels mounted on a south-facing roof or wall, each with transparent cover to admit sunlight. Water circulates through channels or pipes inside each panel. The inside is usually painted black, because black surfaces readily absorb heat. Solar energy can also be used to generate electricity in photovoltaic (PV) cells. A PV cell may power your calculator. Photovoltaic cells are made of semiconductors, similar to those used to make computer chips. Until recently these cells were very costly to produce. However, they are still only about 10-15 per cent efficient. Solar energy can be converted to thermal (or heat) energy and used to: Heat water - for use in homes, buildings, or swimming pools. Heat spaces - inside greenhouses, homes, and other buildings. In this sunlight is converted to electricity indirectly. It is first converted to mechanic energy and later to electric energy. When the heat from solar thermal collectors is used to heat a fluid which produces steam that is used to power generator. Out of the 15 known solar electric generating units operating in the United States at the end of 2006, 10 of these are in California and 5 in Arizona. No statistics are being collected on solar plants that produce less than 1 megawatt of electricity, so there may be smaller solar plants in a number of other states. 


\section{PRINCIPLE OF OPERATION}

\section{A. Basic Topology}

In this section it is presented a modular system,

Synchronized with the electric grid, able to inject low current harmonic content, provide galvanic insulation between the solar panels and the grid. The proposed energy conversion system, composed of three stages is shown in Fig. 1.

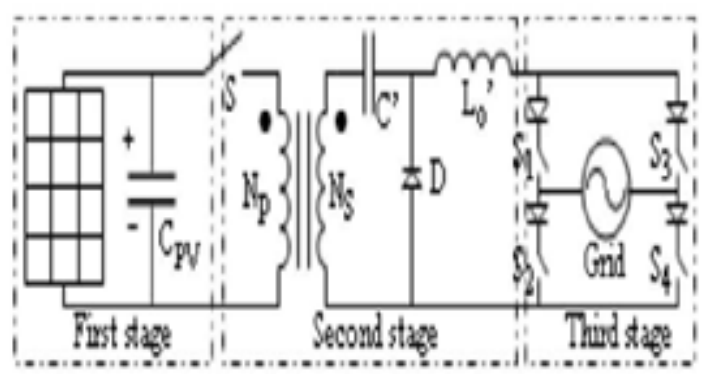

Figure 1. Proposed energy conversion system.

The first stage consists of the solar panel, in parallel with a bulky capacitor Cpv. The second stage consists of an isolated Zeta converter operating in DCM. At this stage it is synthesized a sinusoidal current in absolute value ha in the Inductor La' synchronized with the grid. The third stage consists of a low frequency full bridge inverter

\section{B. Simplifying Assumptions}

The dynamic behavior and the stages of operation of this system will be analyzed further from the following simplifying assumptions:

The transformer has an unitary ratio ( $\mathrm{Ns} / \mathrm{Np}=1)$ and is represented by its magnetizing inductance Lm; - The quasi-static approximations are assumed, hence the output voltage $\mathrm{Va}$ is considered constant within a high frequency switching period; The solar panels associated with the batteries are represented by the $\mathrm{Vg}$ voltage source ;All semiconductors are considered ideal; The converter does not affect the power grid, and the grid may be represented by a simple equivalent resistive load $\mathrm{R}$ that represents the power absorbed by the power grid.

\section{Stages of Operation and Waveforms}

In DCM the converter of presents three stages of Operation, represented schematically The main Converter waveforms within a high frequency period are shown The main converter waveforms within a low frequency period are presented, considering the sinusoidal PWM modulation.

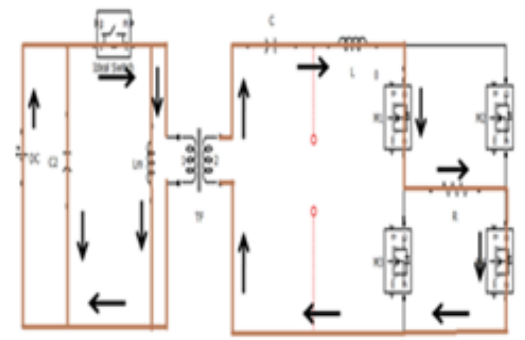

(a)

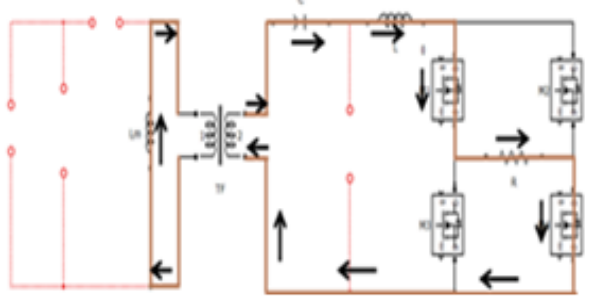

(b)

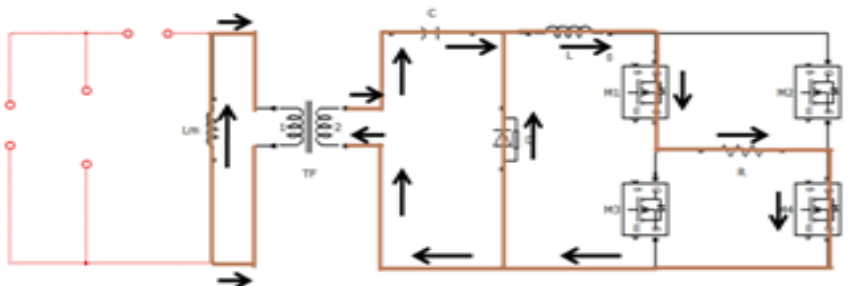

(c)

Figure 2. (a) First, (b) second and (c) third stages of operation Of zeta converter 


\section{Static Gain}

The conduction time of the diode (tD) is constant when there is no variation of the load R in DCM [6]. So, the instantaneous static gain $\mathrm{g}(\mathrm{t})$ of the ZETA converter in DCM can be expressed by (1). This characteristic implies III a linear relationship between the input and output .whereD $=\sim=\sim 2 \mathrm{Leq} \mathrm{fd}(\mathrm{t})$ is the instantaneous duty cycle of the converter, $f$ is the switchingfrequency, $L_{e q}$ is the equivalent inductance ofThe converter and $R$ is the load equivalent resistance .It is possible to conclude that the control-to-output relationship of the converter is also linear, in the steady-state analysis.

\section{GENERALIZED SWITCH AVERAGING TECHNIQUE}

\section{A. The Technique}

The state-space averaging (SSA) technique was first presented in, and previously used successfully in the analysis of the ZETA converter in continuous conduction mode (CCM) and for SEPIC converter in DCM. This method can be extended to the DCM, but in this case it is less accurate, because the converter transfer function is dependent of the load [10]. Another aspect it is that only the coefficients of the matrices are averaged, and not necessarily the state variables themselves [11]. However, it is possible to use the Generalized Switch Averaging technique, where well-known models derived from CCM (including SSA model) may be used in DCM analysis, by including an additional switching network to the model through feedback, $u(t)$ are the independent inputs of the converter. $y(t)$ are the converter outputs. $u,(t)$ are the inputs of the switch network. $y,(t)$ is the output of the switch network. Finally, the input ult) are all the converter control inputs.

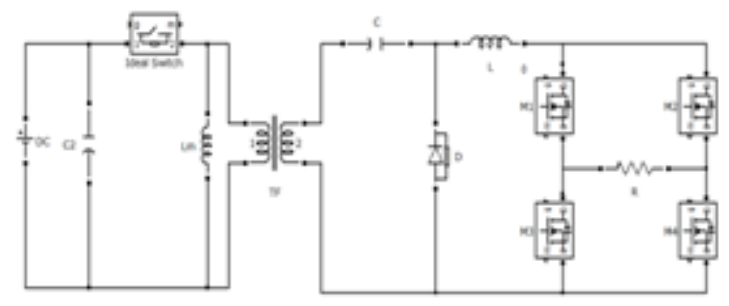

Figure 3. circuit diagram

\section{B. Switch Network}

The system proposed in this paper consists in a similar structure where the step-up converter isimplemented by an isolated ZETA converter [2][3]. Nevertheless, in this case, the ZETA converter has two main functions: adapt the voltage level and synthesize a rectified sinusoidal voltage waveform. In order to obtain a sinusoidal waveform, one of the semicycles of the rectified waveform at the ZETA output must beinverted. A 180 degree phase inverter, operating at lowfrequency $(50 / 60 \mathrm{~Hz})$ is used to perform this function. It is expected a considerable reduction on the switching power losses compared to the typical solution, since the inverter operates at low frequency. As is well know, the ZETA converter has its switch in series with the input power supply (PV), because of this the converter presents high current levels related to other basic fourth-order DC-DC converters like Cuk and SEPICConsequently, the ZETA converter has received less attention. As a result, an accurate analytical dynamic mod

\section{Time Invariant Network}

In this paper, the Time-Invariant Network is SSA model of the ZETA converter working in CCM, but instead of $d(t)$, the averaging model is obtained by means of $\mathrm{fl}(\mathrm{t})$. Considering the converter shown it can be represented in state-space.

$$
\begin{gathered}
\mathrm{X}(\mathrm{t})=\sim \mathrm{X}(\mathrm{t})+\sim \mathrm{u}(\mathrm{t}) \\
\mathrm{Y}(\mathrm{t})=\mathrm{C} \mathrm{x}(\mathrm{t})+\mathrm{Eu}(\mathrm{t}) \\
\mathrm{A}=\mathrm{A}, \mathrm{fl}(\mathrm{t})+\mathrm{A} 2(1-\mathrm{fl}(\mathrm{t})) \\
\mathrm{B}=\mathrm{B}, \mathrm{fl}(\mathrm{t})+\mathrm{B} 2(1-\mathrm{fl}(\mathrm{t})) \\
\mathrm{C}=\mathrm{C}, \mathrm{fl}(\mathrm{t})+\mathrm{C} 2(1-\mathrm{fl}(\mathrm{t}) \\
\mathrm{E}=\mathrm{E}, \mathrm{fl}(\mathrm{t})+\mathrm{E} 2(1-\mathrm{fl}(\mathrm{t}))
\end{gathered}
$$

The state variables $\mathrm{x}(\mathrm{t})$ are the inductor currents ( $\mathrm{hm}$ and $\mathrm{dh}$ ) and the capacitor voltage (ve). In this model, $\mathrm{u}(\mathrm{t})$ contains the independent inputs of the power converter, such as the input voltage $\mathrm{vl} t$ ) and, in some 
cases, the output current. Fl (t) is the switch conversion ratio. The in matrices in (9) are the matrices that describe the behavior of the state variables and the output $y(t)$ at the first and second stage of operation. These matrices will be presented further presented in

The small-signal AC model is obtained by perturbation and linearization. The system perturbations are

$$
\begin{gathered}
X(t)=X+x(t) \\
F l(t)=f l o+f t(t) \\
U(t)=U+u(t) \\
\text { yet })=Y+. \text { Yet }) \\
\text { Us }(t)=u s+u s(t) \\
\text { Ue }(t)=U e+\text { ue }(t)
\end{gathered}
$$

The capital letters are the steady-state values of the variables. The lower case letters with a hat above them are small signal variations. Thus, is the steady-state solution of the system and (12) is the small-signal AC model that contains the dynamic behavior of the converter in CCM.

$$
\begin{gathered}
X=-A^{-1} B U \\
Y=\left(-C A^{-1} B+E\right) U \\
X(t)=A x(t)+B u(t)+B_{D} \mu(t) \\
Y(t)=C x(t)+E u(t)+E_{D} \mu(t) \\
A=A 1 \mu o+A 2(1-\mu o) \\
B=B I \mu o+B 2(1-\mu o) \\
C=C I \mu o+C 2(1-\mu o) \\
E=E I \mu o+E 2(1-\mu o) \\
B_{D}=(A I-A 2) X+(B I-B 2) U \\
E_{D}=(C I-C 2) X+(E I-E 2) U
\end{gathered}
$$

The parameter flo is obtained by evaluating $\mathrm{fl}(\mathrm{VJ}, \mathrm{i} 2, \mathrm{~d})$ or $\mathrm{fl}(\mathrm{V} 2, \mathrm{HD})$ at the quiescent operation point. The linear zed switch conversion isft $(t)=k A(t)+k s u s(t)$

Assuming that the outputs of (12) are the switch network inputs, i.e.

$$
\begin{gathered}
\text { Us }(t)=C x(t)+E u(t)+E D f t(t) \\
F^{\prime \prime} l(t)=k s C^{\prime \prime} x() t+k s E u^{\prime \prime}(t)+k e u^{\prime \prime} e(t)
\end{gathered}
$$

L-ksEd 1-ksEd 1-ksEd first line.

Finally, the dynamic behavior of the converter working in DCM can be obtained by substituting in the

$X(t)=A_{D C M} X(t)+B_{D C M} u(t)+B_{D D C M} U c(t)$

Where

$$
\mathrm{A}_{\mathrm{DCM}}=\mathrm{A}+\mathrm{B}_{\mathrm{D}}-\mathrm{ks} \mathrm{C} / \mathrm{l}-\mathrm{ks} \mathrm{E}_{\mathrm{d}}
$$




$$
\begin{aligned}
& \mathrm{B}_{\mathrm{DCM}}=\mathrm{B}+\mathrm{B}_{\mathrm{D}}-\mathrm{ks} \mathrm{E} / \mathrm{l}-\mathrm{ks} \mathrm{E}_{\mathrm{d}} \\
& \mathrm{B}_{\mathrm{DDCM}}=\mathrm{B}_{\mathrm{D}} \mathrm{Kc} / 1-\mathrm{ks} \mathrm{E}_{\mathrm{d}}
\end{aligned}
$$

Note that the system does not have the switch conversion ratio at its input anymore because the real controllable input is the duty cycle, represented by Uc.

\section{DYNAMIC MODELING}

It is necessary to define the system inputs and outputs. The converter of Fig. 3 has one control input and one independent input.

$$
\begin{aligned}
& \mathrm{U}(\mathrm{t})=[\operatorname{vg}(\mathrm{t})] \\
& \mathrm{Uc}(\mathrm{t})=[\mathrm{d}(\mathrm{t})]
\end{aligned}
$$

$\mu\left(V_{D}(t), \operatorname{lsw}(t), d(t)\right)=1 / 1+\operatorname{Re}(d(t)) i_{s w}(t) / V_{D}(t)$

Leads to the quiescent switch conversion ratio for the ZETA converter.

$$
\mu o=D / D+D_{I}
$$

The gains kc and ks may be found applying

$$
\begin{gathered}
\mathrm{K}_{\mathrm{c}}=2 \mathrm{D}_{1} /\left(\mathrm{D}+\mathrm{D}_{\mathrm{I}}\right) \\
\mathrm{Ks}=\operatorname{Re}(\mathrm{D}) / \mathrm{v}_{\mathrm{gx}} \mathrm{DD}_{1} /\left(\mathrm{D}+\mathrm{D}_{\mathrm{I}}\right)^{2} \\
\mathrm{Ks}=1 / \mathrm{v}_{\mathrm{g}} \mathrm{D}_{1}{ }^{2} /\left(\mathrm{D}+\mathrm{D}_{\mathrm{I}}\right)^{2}
\end{gathered}
$$

Applying Kirchhoff's law in the circuits. it is possible to obtain the equations that describe the behavior of the system at each stage of operation. From the first stage results,

$$
\begin{gathered}
\mathrm{di}_{\mathrm{Lm} /} \mathrm{dt}=1 /{ }_{\mathrm{Lm}} * \mathrm{~V}_{\mathrm{g}} \\
\mathrm{di}_{\mathrm{Lo}} / \mathrm{dt}=1 / \operatorname{Lo}\left(-\mathrm{Ri}_{\mathrm{Lo}}-\mathrm{V}_{\mathrm{c}}+\mathrm{V}_{\mathrm{g}}\right)
\end{gathered}
$$

It is not necessary to modeling the third stage of operation, once in the context of this work, the time-invariant network is a SSA model of the ZETA converter working in CCM.

\section{CONVENTIONAL METHOD 1 BOOST INVERTER WITHOUT ISOLATION}

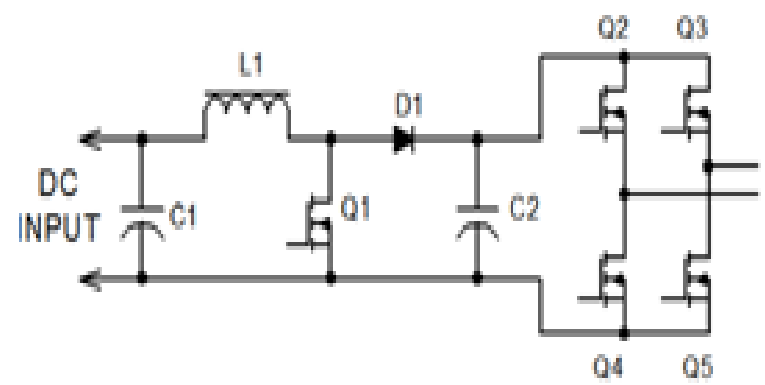

\section{DRAWBACKS}

- $\quad$ Direct effect of input output voltage

- $\quad$ Not suitable for high power conversion

- Low amount of de step up

- non isolated inverter 


\section{CONVENTIONAL METHOD 2 FULL BRIDGE WITH ISOLATION}
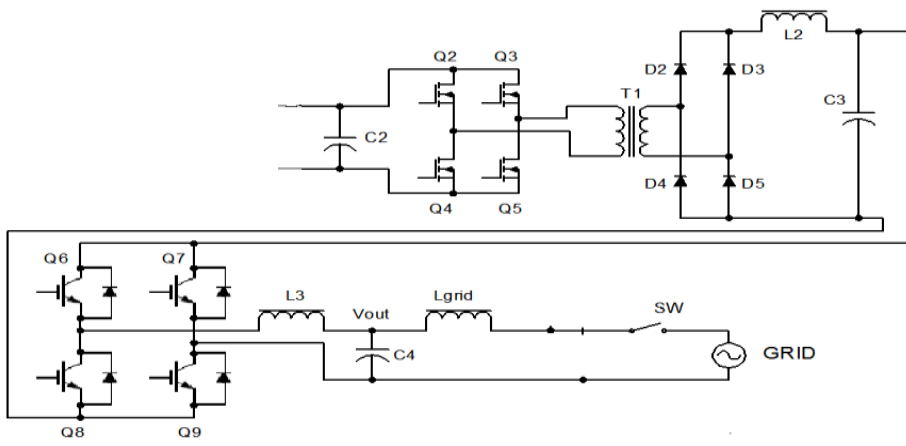

\section{DRAWBACKS}

- Transformer ratio is more

- No of switches is more

- Not suitable for low input due to control rectifier

- High voltage stress

- Cost high

\section{SIMULATION RESULTS}

The control-to-output dynamic model was obtained using an algorithm in the software MATLAB TM and validated using the circuit of on the power simulation software PSIMTM. shows the bode diagram of the control-to output.

Transfer function at the operational point $\mathrm{D}=0.5$, considering the current in the output inductor as the converter output. Fig. 10 presents the step response of the obtained model and the simulated results from PSIMTM. The values of the components involved in the simulation are presented in Table I.

\begin{tabular}{|l|l|l|}
\hline \multicolumn{1}{|c}{ TABLE I. COMPONENT V ALVES } \\
\hline Component & \multicolumn{1}{|c|}{ Definition } & Value \\
\hline & & \\
$\mathrm{R}$ & Equivalent Load Resistance & $130 \mathrm{n}$ \\
$\mathrm{Lm}$ & Magnetizing inductance & $8711 \mathrm{H}$ \\
$\mathrm{Lo}$ & Output inductance & $22 \mathrm{mH}$ \\
$\mathrm{C}$ & Coupling capacitance & $680 \mathrm{nF}$ \\
$\mathrm{Vg}$ & Input voltage & $34 \mathrm{~V}$ \\
$\mathrm{~F}$ & Switching frequency & $20 \mathrm{KHz}$ \\
$\mathrm{D}$ & Duty-cycle at operating point & $47 \%$ \\
\hline
\end{tabular}

To simulate and implement Zeta Converter to Achieve high setup voltage with low input

- Single switch isolation

- Low voltage Stress

- Reduce transformer ratio

- Low cost systems

PRIMARY VOLTAGE \& SECONDARY VOLTAGE

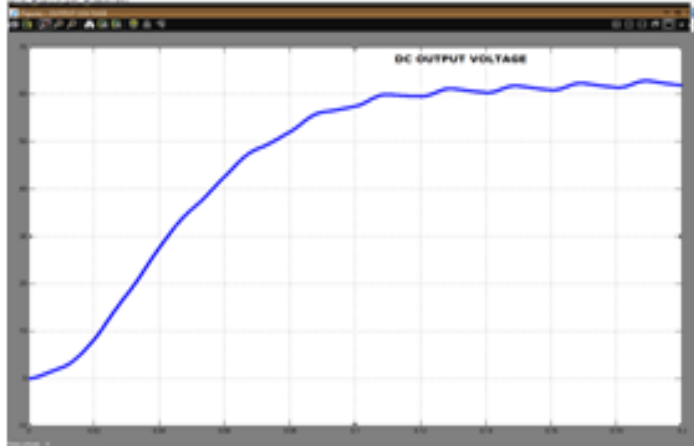

DC OUTPUT VOLTAGE

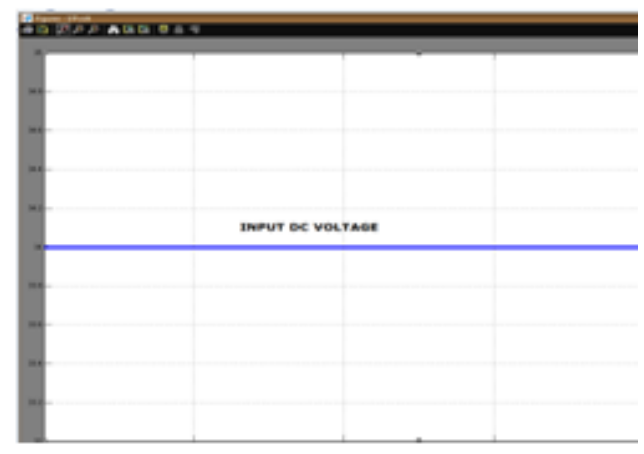

INPUT DC VOLTAGE

www.iosrjen.org 


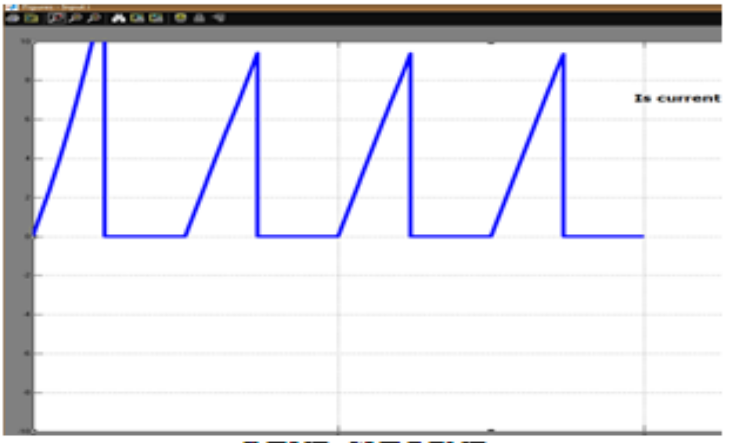

INPUT CURRENT

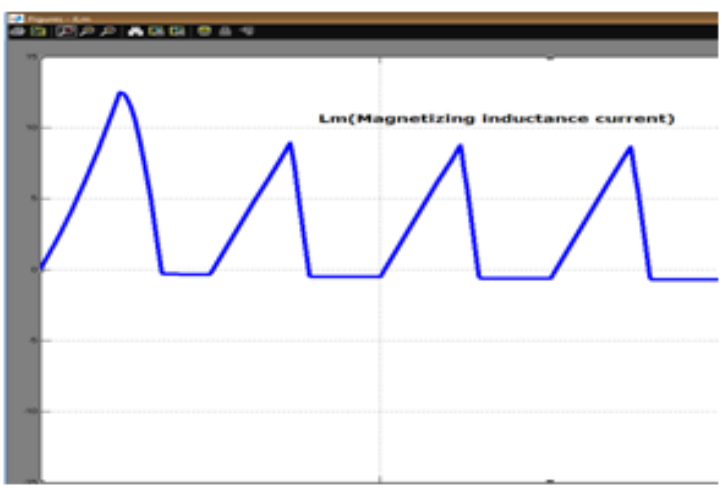

LM CURRENT

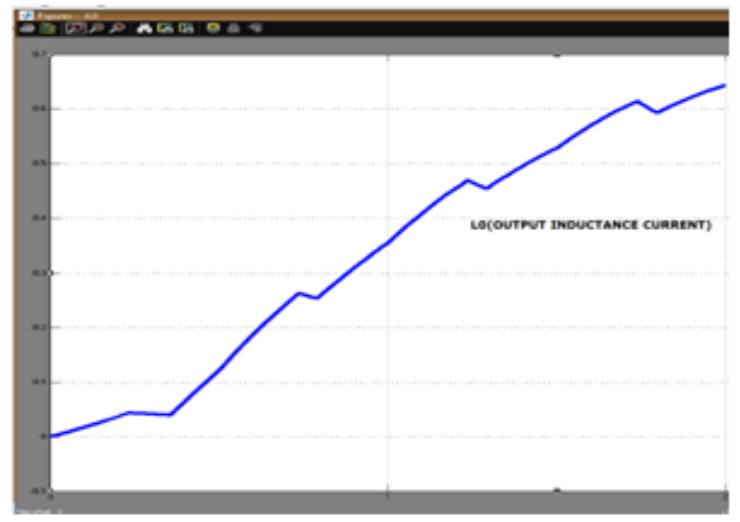

OUTPUT INDUCTANCE CURRENT

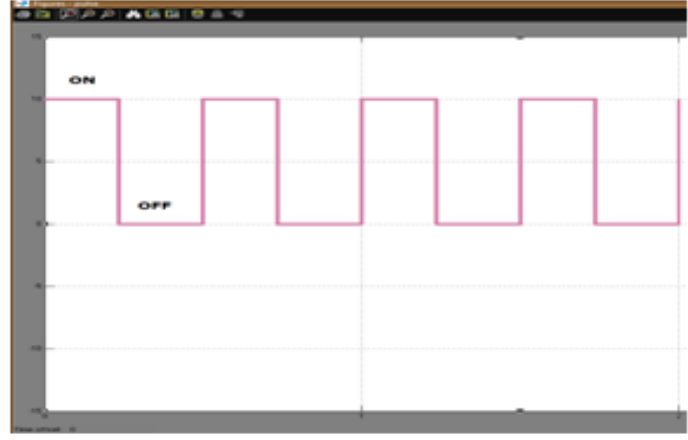

TRIGGERING PULSES

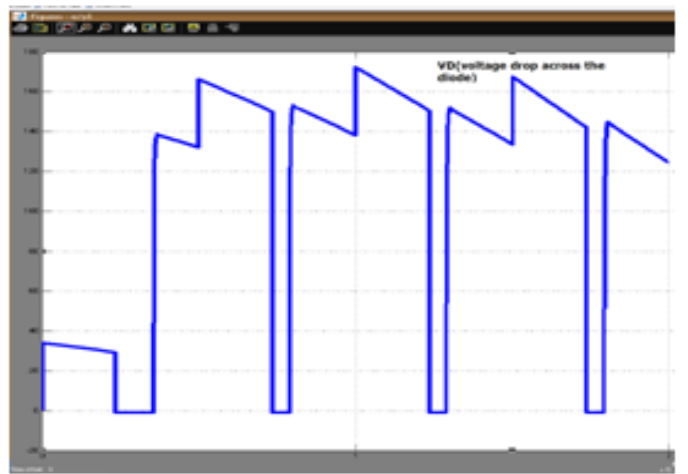

OLTAGE DROP ACROSS THE DIODE

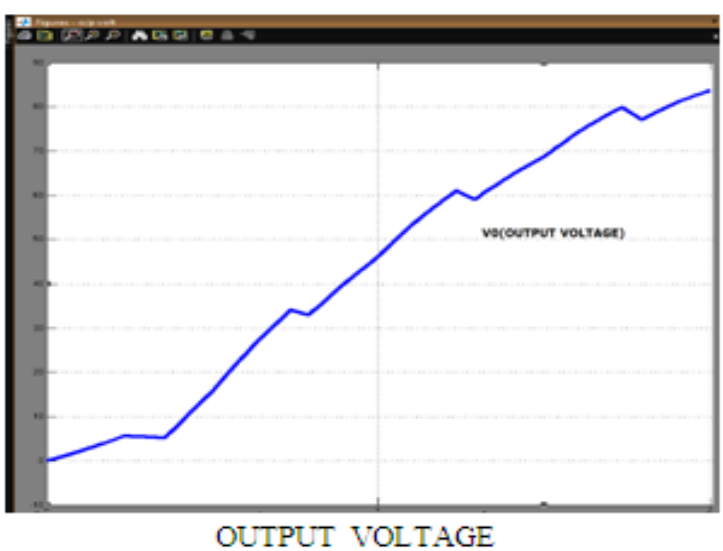

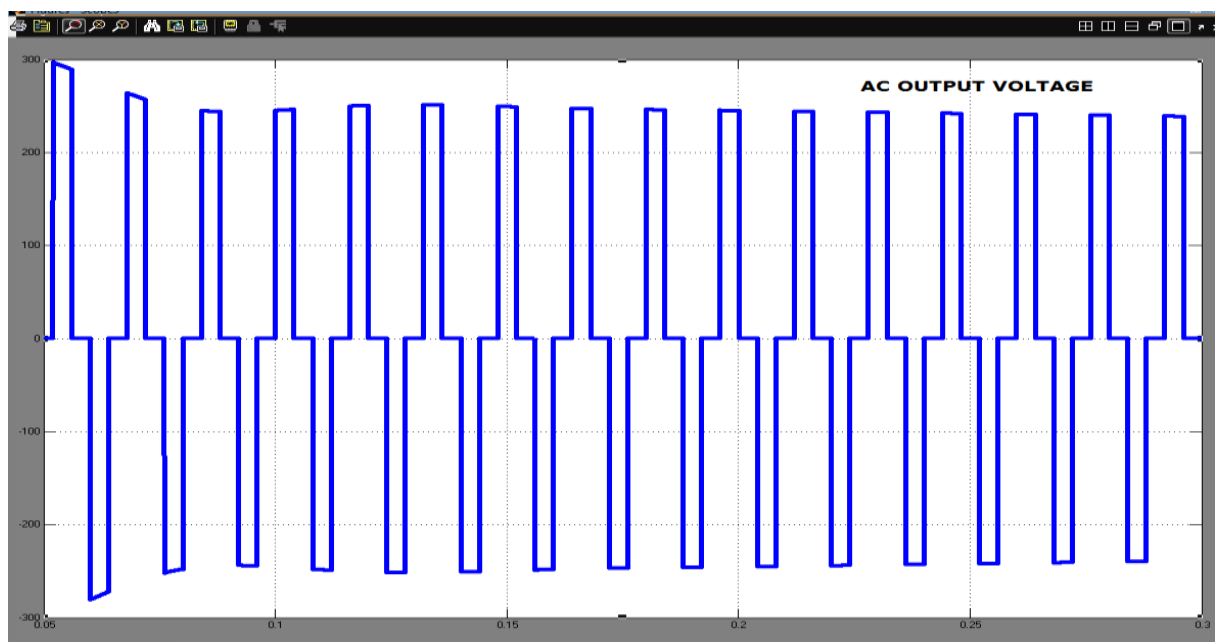

AC OUTPUT VOLTAGE 

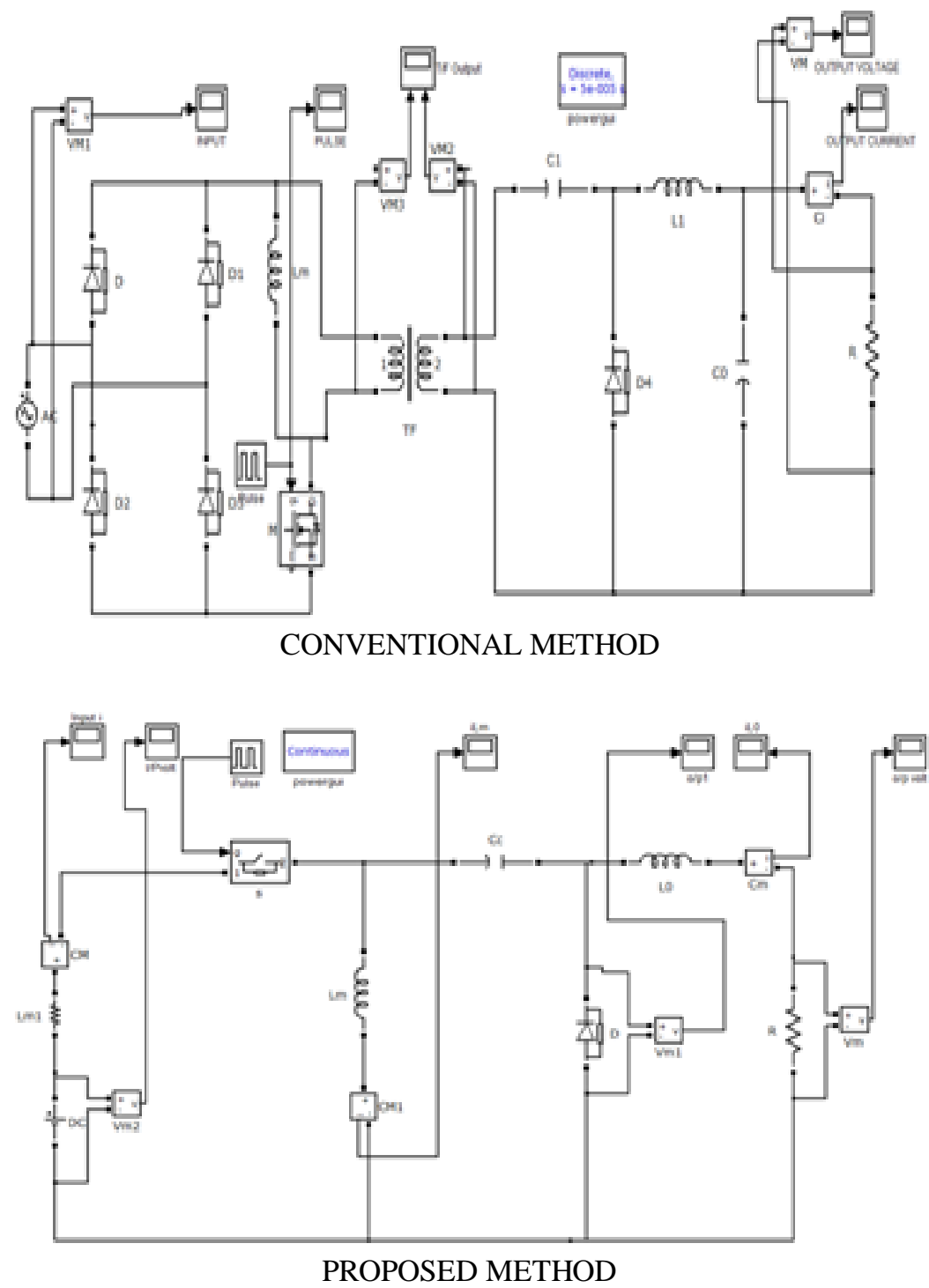

VI. CONCLUSIONS

This paper presents a dynamic modeling of a ZETA converter in discontinuous conduction mode (DCM) applied to low power renewable sources using the generalized switch averaging technique. In this work was developed an unpublished dynamic model of the Zeta converter working in DCM. The obtained results had shown that the proposed model is extremely accurate. It is therefore, useful for the development of the control strategies for the Zeta converter working in the DCM. The peak time and the current overshoot obtained by the proposed model had presented results nearly identical to simulated and experimental results. An AC analysis was performed in software PSIM ${ }^{\mathrm{TM}}$, this study shown that the Bode diagram generated from the proposed model is accurate. Finally, it is important to remark that the implementation of the model us mg the software

MATLAB TM allows the development of a more precise control strategy. The conventional and proposed methods have been analyzed and discussed with advantages and disadvantages of each method. In future, simulation of both conventional and proposed method will be done. And hardware will be designed and implemented for the proposed method. Finally Simulation output and the hardware output of the proposed method will be verified and compared. In this paper was presented a dynamic model for a ZETA converter in DCM applied to low power renewable sources using the SSA technique. Even with the the DCM analysis, the dynamic model obtained by the generalized average technique showed severalsimilaritieswith the simulated system. It was shown that the dynamic characteristic of the converter almost does not change with changes in duty cycle, facilitating the development of control strategies for applications where a wide range of values of duty cycle is required. The obtained experimental results support the proposal. The simplicity of the system results in a low cost structure and therefore suitable to apply in u governmental programs to stimulate the use of renewable energy sources. 


\section{REFERENCES}

[1]. Departamento de Estado dos EUA. "Soluyoes de Energia Limpa".eJoumal USA: Perspectivas Economicas. Vol 11. nO 2. 2006.

[2]. J. A. Pomilio. "Pre-reguladores de Fator de Potencia". Publicayao FEE 03 /95. 2007.

[3]. H. F. M. Lopez, C. Zollmann, R. C. Viero and F. S. dos Reis."Photovoltaic Panels Grid-Tied By a Zeta Converter". BrazilianPower Electronics Conference, pp. 1-6.2009.

[4]. A. Peres, D. C. Martins and I. Barbi. "ZETA Converter Applied in Power Factor Correction". IEEE Power Electronics Specialists Conf.,pp. 1152-1157. 1994.

[5]. H. F. M. Lopez, R. C. Viero, C. Zollmann, L. L. Reckzielgel, R. Tonkoski, F. S. dos Reis. Low Power Solar System Grid-Tied With MPPT Based on Temperature Compensation. The 9th Annual Electrical Power and Energy Conference - EPEC. 2009.

[6]. D. C. Martins, I. Barbi. "Eletronica de Potencia: Conversores CC-CCBasicos nao Isolados". 3th ed., Author's Edition. Fiorianopolis, SC.2008.

[7]. Middlebook, R. D. and Cuk, S. A General Unified Approach to Modeling Switching-Converter Power Stages. International Journal of

[8]. Electronics, Vol. 42, pp. 521-550. 1977.

[9]. Eng, V. and Bunlaksananusorn, C. Dynamic Modeling of a Zeta Converter with State-Space Averaging Technique. Proc. of ECTICON 2008, pp. 969-972. 2008.

[10]. Eng, V. and Bunlaksananusom, C. Modeling of a SEPIC Converter Operatng in Discontinuous Conduction Mode. Proc. of ECTI-CON 2009, pp. 140-143 . 2009.

[11]. Erickson R. W. Fundamentals of Power Electronics. International Thomson Publishing. 1997.

[12]. 11] Sun, J; Mitchell, D. M; Greuel, M. F; Krein, P.T and Bass, R. M. Averaged modeling of PWM converters operating in discontinuous conduction mode. IEEE Trans. on Power Electronics. Vol. 16, No. 4. 2001.

[13]. Singer, S. Realization of Loss-Free Resistive Elements. IEEE Trans. on Circuits and Systems. Vol. CAS37, No. I, pp. 54-60. 1990. 